\title{
Knowledge, Attitudes and Practices of Caregivers in Relation to Oral Health of Preschool Children
}

\author{
Fatima Ashkanani Mona Al-Sane \\ Faculty of Dentistry, Kuwait University, Jabriya, Kuwait
}

\section{Key Words}

Knowledge $\cdot$ Attitude $\cdot$ Practice $\cdot$ Children $\cdot$ Early childhood caries $\cdot$ Infant oral health

\begin{abstract}
Objective: To assess the knowledge, attitudes and practices of caregivers in Kuwait in relation to the oral health of preschool children. Subjects and Methods: Questionnaires with multiple-choice questions were distributed to 334 caregivers of children under the age of 6 years attending vaccination centers in Kuwait. For each question, one of the multiple-choice answers was consistent with the consensus in the pediatric dental literature in relation to early childhood caries prevention, and was considered to be correct. The $\chi^{2}$ test, independent $t$ test, ANOVA, and stepwise linear regression were used to assess the associations between the variables in question and $p \leq 0.05$ was accepted as statistically significant. Results: Of the 334 participants, 234 (70\%) were between 20 and 40 years of age with a high school diploma or higher degree and had between 2 and 5 children. The mean knowledge score was $4.68 \pm 1.87$, the mean attitude score was $4.34 \pm 0.88$ and the mean practice score was $2.45 \pm$ 0.99 . Major weaknesses were reported in infant oral healthrelated concepts. Mothers had better knowledge than other caregivers $(p<0.001)$. Higher education was significantly associated with better knowledge $(p=0.003)$ and better prac-
\end{abstract}

\section{KARGER}

E-Mail karger@karger.ch www.karger.com/mpp
(C) 2012 S. Karger AG, Basel 1011-7571/13/0222-0167\$38.00/0

Karger

Open access

This is an Open Access article licensed under the terms of the Creative Commons Attribution- NonCommercial-NoDerivs 3.0 License (www.karger.com/OA-license), applicable to the online version of the article only. Distribution for non-commercial purposes only. tices ( $p=0.017)$. In addition, knowledge, attitude and level of education were positively and significantly associated with practices $(p<0.005)$. Conclusions: Our study showed that caregivers had weak knowledge and practice in relation to the oral health of preschool children. Mothers and caregivers with higher education had better knowledge and practices. Education and attitude appeared to be favorable indicators of the caregivers' practices with regard to the oral health of their preschool children.

Copyright $\odot 2012$ S. Karger AG, Basel

\section{Introduction}

Severe early childhood caries (S-ECC) is a specific form of rampant caries affecting the primary dentition of infants and preschool children [1]. The American Academy of Pediatric Dentistry currently defines S-ECC as 'Any sign of smooth-surface caries in a child younger than 3 years old. From ages 3 to 5, 1 or more cavitated, missing (due to caries) or filled smooth surfaces in primary maxillary anterior teeth, or a dmf score of $\geq 4$ (age 3 ), $\geq 5$ (age 4 ) or $\geq 6$ (age 5) surfaces is indicative of $S$ ECC' [2]. The consequences of untreated caries in children include an increased risk for developing new carious lesions in both the primary and permanent dentitions [2]. In addition, there is strong evidence of the positive cor- 
relations between untreated S-ECC and failure to thrive, delayed social and intellectual development and impaired oral health-related quality of life [2]. Early childhood caries (ECC) is a multifactorial disease with an etiology that involves a complex interaction between biological, social and economic factors [3-10]. The disease remains highly prevalent among ethnic minorities and populations with certain disadvantaged family characteristics in many parts of the world $[8,9]$. Factors such as social deprivation, income inequality and poor social cohesion have been linked to increased caries prevalence $[8,9]$. It is estimated that almost one quarter of ethnic minority and underprivileged children between the ages of 2 and 5 in the United States have had caries and that close to $20 \%$ of children in the same age group have untreated caries [11]. In less developed parts of the world, the disease prevalence pattern and the complex interaction between dental health and social and economic factors remains understudied. The western model of ECC dynamics, etiology and prevalence may, therefore, not be fully applicable to these countries. An example of this is Kuwait, an oil-rich state with high health care standards, no perceived difficulties with access to care, and a well-developed extended family network and support system with prevalent social cohesion; yet caries remains to be a significant problem among children in Kuwait. Currently, there are no well-designed, nationwide epidemiological studies assessing the prevalence of ECC, S-ECC or untreated dental disease among children under 6 years of age in Kuwait. However, some data could be extracted from the national oral health surveys conducted in the 1980s, 1990s and 2000s [12-17]. The percentage of 5-year-old children in Kuwait who are free of dental caries increased from $20.6 \%$ in 1982 to $30.4 \%$ in 1985 , but decreased to $12.6 \%$ in 2000 . Moreover, the mean dmf scores of 6-year-olds increased from 3.9 in 1985 to 4.6 in 2000 [12-17]. Drinking water has been nonfluoridated since the early 1990s. Local efforts in managing the disease burden among preschool children in Kuwait have focused primarily on improving access to care at community clinics and periodic fluoride varnish application for kindergarten children. However, such strategies have failed to control the disease prevalence. Recent child oral health literature has emphasized the role of caregivers in oral health and disease prevention [7, 18-22]. There is strong evidence linking the health literacy of caregivers, defined as the comprehension and effective use of health information in making health choices, to early childhood health-related behaviors. Improving health literacy in a population should be looked at as a desired outcome to a successful health promotion program. Such outcomes involve more than health information transmission. The social and economic factors of the population need be taken into consideration $[9,10$, 18-20, 23]. Therefore, developing an effective oral health promotion strategy in any given community must be based on an in-depth understanding of the unique needs of the population. A simple assessment of the knowledge, attitude and practice (behavior) levels may be the first step in identifying areas of weakness. Thus, the aims of this study were to assess the level of the knowledge, attitudes and practices of caregivers in Kuwait with regard to the oral health of preschool children.

\section{Subjects and Methods}

This was a cross-sectional study conducted using an anonymous self-administered questionnaire on a sample of 334 caregivers from Kuwait. The study took place at vaccination centers from all six geographic districts of Kuwait. The inclusion criterion was being a caregiver for a preschool child (under 6 years of age). A total of 334 caregivers were invited to participate. Given an alpha of 0.05 , an effective size of 0.10 and four predictors, statistical power with a sample of 200 was determined to be 0.98 . Therefore, with a sample of 334 , statistical power was high at 0.98 . The questionnaire used in this study was developed by the primary investigator (F.A.) and was written in Arabic. It included 18 questions assessing the knowledge, attitudes and practices of caregivers towards the oral health of their preschool children as well as some demographic questions. The questionnaire was piloted before the start of the study. Some questions were then reworded to improve clarity. A response matrix with the correct knowledge and the ideal attitude and practice answers were prepared using the 2011 American Academy of Pediatric Dentistry guidelines as well as consensus in the current pediatric dental literature with regard to early childhood (infant and preschool) oral health [1, 2, 4, 7, 18]. The responses were then rated as either consistent or inconsistent with the answers in that matrix. Data were descriptively analyzed, and a $\chi^{2}$ test was used to determine the relationship between the individual knowledge, attitude and practice questions and the sociodemographic characteristics of the participants. An independent $t$ test and ANOVA were also used to determine whether the overall knowledge, attitudes and practices varied across different sociodemographic variables. A stepwise linear regression procedure was conducted to determine the relationship between education, knowledge, attitude and practice. The level of significance in this study was chosen at $\mathrm{p} \leq 0.05$. SPSS version 17.0 (SPSS Inc., Chicago, Ill., USA) was used for the data analysis.

\section{Results}

All 334 questionnaires were completed and returned by the participants from all six geographic districts of Kuwait, thereby giving a response rate of $100 \%$. Of the 
334 participants, 234 (70\%) were between 20 and 40 years of age. In addition, 115 (34\%) had a university degree or higher, 171 (51\%) had a monthly income of KD 1,000 (approx. USD 3,300) or higher, $182(54 \%)$ were mothers and $223(67 \%)$ had between 2 and 5 children. Also, 273 (82\%) completed the questionnaire while on a vaccination visit for a child between 2 and 5 years of age (table 1).

\section{Knowledge}

The overall mean knowledge score was $4.68 \pm 1.87$ (range 0-9). Mothers had significantly better overall knowledge scores than fathers and other caregivers $(\mathrm{p}<$ 0.001 ). In addition, participants with a university educational level or higher had significantly better overall knowledge scores than less educated participants $(\mathrm{p}=$ 0.003).

The percentage of participants who answered correctly for individual knowledge questions is shown in figure 1 . When asked about food cariogenicity and the importance of fluorides in caries prevention, 304 (91.3\%) of the participants answered correctly. However, only 82 $(24.6 \%)$ were aware of the right time to start brushing a child's teeth and the ideal time for the first dental visit. Older participants ( $>40$ years of age) had significantly better knowledge in areas such as the effect of untreated caries on growth $(\mathrm{p}=0.020)$, while younger participants had significantly better knowledge with regard to the ideal timing for the child's first dental visit $(\mathrm{p}=0.011)$. Additionally, mothers of children aged $0-1$ years had significantly better knowledge with regard to the ideal time to start brushing a child's teeth $(\mathrm{p}=0.000)$

\section{Attitudes}

The overall mean attitude score was $4.34 \pm 0.88$ (range $0-5$ ). The overall attitude scores were not significantly associated with the demographic variables recorded in this study. The percentage of participants who correctly answered individual attitude questions is shown in figure 1 . The more educated participants had a significantly better appreciation of the importance of baby teeth $(\mathrm{p}=0.035)$. Also, mothers had a better appreciation of the importance of regular dental visits compared to other caregivers $(\mathrm{p}=0.000)$.

\section{Practices}

The overall mean practice score was $2.45 \pm 0.99$ (range $0-4$ ). The education level of the caregiver had a significant effect on their practices $(\mathrm{p}=0.017)$. Participants who did not complete a high school education had lower mean practice scores than those with a higher edu-
Table 1. Characteristics of the caregivers $(n=334)$ and children in this study

\begin{tabular}{|c|c|c|}
\hline Characteristics & $\mathrm{n}$ & $\%$ \\
\hline \multicolumn{3}{|l|}{ Age, years } \\
\hline$<20$ & 34 & 10 \\
\hline $20-40$ & 233 & 70 \\
\hline$>40$ & 42 & 13 \\
\hline No answer & 25 & 7 \\
\hline \multicolumn{3}{|l|}{ Education } \\
\hline$<$ High school & 61 & 18 \\
\hline High school/diploma & 145 & 43 \\
\hline University/higher education & 115 & 34 \\
\hline No answer & 13 & 4 \\
\hline \multicolumn{3}{|l|}{ Household income } \\
\hline$<\mathrm{KD} 1,000$ (USD 3,300) & 156 & 47 \\
\hline KD 1,001-2,000 (USD 3,300-6,600) & 151 & 45 \\
\hline KD 2,001-3,000 (USD 6,600-9,900) & 16 & 5 \\
\hline$>\mathrm{KD} 3,000(>9,900 \mathrm{USD})$ & 4 & 1 \\
\hline No answer & 7 & 2 \\
\hline \multicolumn{3}{|l|}{ Relationship to child } \\
\hline Father & 130 & 39 \\
\hline Mother & 182 & 54 \\
\hline Other ${ }^{a}$ & 18 & 5 \\
\hline No answer & 4 & 1 \\
\hline \multicolumn{3}{|l|}{ Number of children in family } \\
\hline 1 & 55 & 17 \\
\hline $2-5$ & 223 & 67 \\
\hline$>5$ & 43 & 13 \\
\hline No answer & 13 & 4 \\
\hline \multicolumn{3}{|l|}{ Age of child, years } \\
\hline $0-1$ & 38 & 11 \\
\hline $2-3$ & 137 & 41 \\
\hline $4-5$ & 136 & 41 \\
\hline No answer & 22 & 7 \\
\hline
\end{tabular}

${ }^{a}$ Grandparents, nannies.

cation. An analysis of the practice scores for individual questions (fig. 1) showed that $250(75 \%)$ of the participants exposed their preschool child to no more than 3 sugar attacks per day, and $267(80 \%)$ indicated that the frequency of brushing their child's teeth was 2-3 times a day. However, it was interesting to note that $146(44 \%)$ of the children had their teeth brushed by a caregiver other than a parent. In addition, $126(37 \%)$ reported that the child's first dental visit was before the age of 3 . The parents with more than 5 children were significantly less likely to limit daily sugar exposures $(\mathrm{p}=0.021)$, brush the child's teeth $2-3$ times a day $(\mathrm{p}=0.030)$ or take the child to the dentist before the age of $3(\mathrm{p}=0.00)$. Older $(>40$ years of age) caregivers were more committed to having 
Fig. 1. Percentage of correct answers for knowledge, attitude and practice questions.

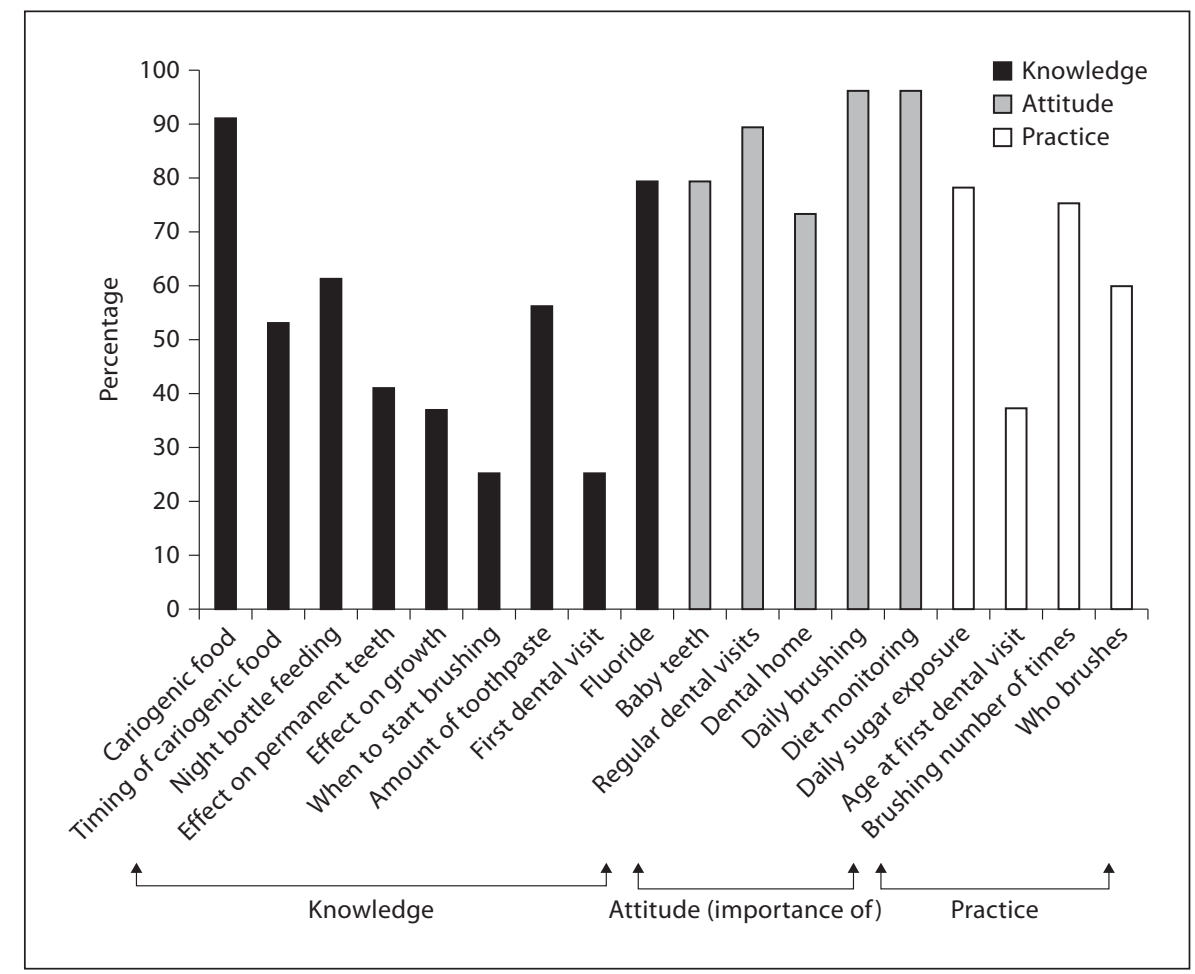

their child's teeth brushed by a parent $(\mathrm{p}=0.040)$. On the other hand, the caregivers of younger children ( $0-1$ years) were more likely to take their children to the dentist before the age of $3(\mathrm{p}=0.000)$.

\section{Factors Associated with Good Practices}

Education, attitude and knowledge were positively and significantly related to the practices of the caregivers regarding the oral health of preschool children $\left[\mathrm{F}(4,329)=12.68, \mathrm{p}=0.001, \mathrm{R}^{2}=0.134\right]$. Having a university degree or higher $(\beta=0.21, p=0.002)$ and having a positive attitude $(\beta=0.21, p<0.001)$ had the strongest association with good practice, followed by having a high school degree as the highest educational level $(\beta=0.19$, $p=0.005$ ). Knowledge, however, had the weakest association with practice compared to the predictors mentioned above $(\beta=0.15, \mathrm{p}=0.007)$.

\section{Discussion}

This study aimed to assess the knowledge, attitudes and practices in relation to the oral health of preschool children among caregivers in Kuwait. The study results showed that the education and attitude of the caregivers strongly correlated with the practices and confirmed the findings of earlier studies [3, 6, 17-20]. Knowledge, however, was weakly correlated with practice, confirming earlier findings, which suggested that changing healthrelated behaviors takes more than just improving knowledge $[7,12,22]$. Social, economic and environmental factors play a substantial role in shaping people's behavior and translating this knowledge into positive health choices and practices [7]. In addition, the results of this study highlighted some general trends that were not always statistically significant but yet are worth noting. The first was a general weakness in the knowledge, attitude and practice in infant oral health-related areas such as the timing for the first dental visit, the ideal timing to initiate tooth brushing for children, as well as nighttime bottle feeding. Better infant oral health-related trends, however, were observed with younger caregivers and caregivers of children under 1 year. This is possibly due to higher educational levels among the younger group. Additionally, younger parents have generally better computer/internet literacy and would therefore have wider access to a variety of oral health-related knowledge. The second observed trend was that mothers, compared to other caregivers, were generally more knowledgeable, had better attitude, but did not necessarily have better practices. This may be 
due to the fact that mothers are usually more involved with the daily care of their children compared to other caregivers.

The results of this study identified some areas of strength and weakness in the knowledge of caregivers. The majority of the participants were knowledgeable about the cariogenicity of sugary food and the preventive effect of fluoride, concepts that are repeatedly being reinforced in the media and in local health care setups. Knowledge with regard to infant oral health-related concepts was much weaker, possibly due to the fact that, in Kuwait, infant oral health-related messages are rarely encountered in the local media or local health care setups as findings in the UK [17] and Hong Kong [20] have shown. This is in contrast to studies with Canadian mothers [18]. This discrepancy may be due to a greater emphasis on infant oral health-related concepts, and the risks of untreated ECC, in oral health promotion and prenatal oral health education programs in North America (USA and Canada) than in many other parts of the world $[2,4,7,18]$. The majority of our study participants exhibited a positive attitude towards concepts they had good knowledge about. In relation to less familiar concepts such as the importance of baby teeth and having a 'dental home', attitudes appeared to be less positive. Support for these findings may be found in studies from Hong Kong [17] and Iran [19], whilst more positive results were reported from Canada [18], with participants exhibiting more proactive attitudes towards the importance of baby teeth.

The results of this study highlighted serious weaknesses in the practices of the caregivers. Although most participants reported limiting the number of daily sugar attacks and brushing the child's teeth 2-3 times a day, close to $44 \%$ of the caregivers reported that their child's teeth were brushed by a caregiver other than a parent. This practice was significantly more prevalent among caregivers younger than 40 years of age. Extended family networks provide a lot of support for caregivers, especially younger ones. Many younger parents are busy forwarding their careers; juggling family and professional responsibilities is not always an easy task. They would, therefore, rely on their support network to deliver the necessary day-to-day care to their children. Additionally, most families in Kuwait hire domestic helpers and nannies to assist in caring for their children. The majority of Kuwaiti parents, particularly mothers, view this support network as a source of help rather than a substitute to their role of being closely involved in caring and supervising the care delivered to their children. Our study find- ings indicated that the caregivers who were involved in the care of more than 5 children had overall weaker practices. This may be due to the overwhelming responsibilities involved in being the primary caregiver to a large family, even in the presence of support network of extended family and domestic helpers.

One of the study limitations is that it was conducted on a convenience sample, although the sample was taken from all six geographic districts of Kuwait, representing the social, economic and educational diversities in the population. The results of this study can thus be viewed as preliminary findings that need to be further explored in future studies conducted on representative samples of caregivers from Kuwait. In addition, attitude-related questions in the questionnaire used in this study assessed general oral health rather than oral health concepts related to preschool children. This may explain the high attitude scores in this study. This needs to be verified in future studies, which should preferably be conducted using a prevalidated questionnaire.

\section{Conclusion}

Caregivers in Kuwait seemed to have weak knowledge and practice in relation to the oral health of preschool children. In addition, there is a strong need to address infant oral health-related issues in future oral health promotion efforts in Kuwait. Knowledge was weakly related to the practices of the caregivers. Education and attitude, however, had a stronger and more significant relationship to the practices of the caregivers.

\footnotetext{
References

$\rightarrow 1$ Ripa LW: Nursing caries: a comprehensive review. Pediatr Dent 1988;10:268-282.

2 American Academy of Pediatric Dentistry: Policy on early childhood caries (ECC): classifications, consequences, and preventive strategies. Pediatr Dent 2008/2009;30:4043.

3 Williams NJ, Whittle JG, Gatrell AC: The relationship between socio-demographic characteristics and dental health knowledge and attitudes of parents with young children. Br Dent J 2002;193:651-654.

4 Borssen E, Stecksen-Blicks C: Risk factors for dental caries in 2-year-old children. Swed Dent J 1998;22:9-14.

5 Stroebe W, Stroebe M: Social Psychology and Health, ed 1. Buckingham, Open University Press, 1995.
} 
6 Szatko F, Wierzbicka M, Dybizbanska E, Struzycka I, Iwanicka-Frankowska E: Oral health of Polish three-year-olds and mothers' oral health-related knowledge. Community Dent Health 2004;21:175-180.

7 Vann WF Jr, Lee JY, Baker D, Divaris K: Ora health literacy among female caregivers: impact on the oral health outcome in early childhood. J Dent Res 2010;89:1395-1400.

$\checkmark 8$ Pattussi MP, Marcenes W, Croucher R, Sheiham A: Social deprivation, income inequality, social cohesions and dental caries in Brazilian schoolchildren. Soc Sci Med 2001;53: 915-925.

$>9$ Watt RG: Emerging theories into the social determinants of health: implications for oral health promotion. Community Dent Oral Epidemiol 2002;30:241-247.

10 Akpata ES, Al-Attar A, Sharma PN: Factors associated with severe caries among adults in Kuwait. Med Princ Pract 2009;18:93-99.

11 Dye BA, Tan S, Smith V, Lewis BJ, Barker LK, Thornton-Evans G, Eke PI, Beltran-Aguilar ED, Horowitz AM, Li CH: Trends in ora health status: United States, 1988-1994 and 1999-2004. Vital Health Stat 11 2007;248: $1-92$.
12 Behbehani JM, Scheutz F: Oral health in Kuwait. Int Dent J 2004;54(suppl 1):401-408.

13 Behbehani JM, Shah NM: Oral health in Kuwait before the Gulf War. Med Princ Prac 2002;11(suppl 1):36-43.

14 Vigild M, Skougaard M, Hadi RA, Al-Zaabi F, Al-Yasseen I: Dental caries and dental fluorosis among 4-, 6-, 12- and 15-year-old children in kindergartens and public schools in Kuwait. Community Dent Health 1996; 13:47-50.

15 Glass RL: Kuwait national dental health survey. Part I. The oral health of school children 6-16 years of age in Kuwait 1982. Kuwait Ministry of Health, 1982.

16 Al-Mutawa SA, Shyama M, Al-Duwairi Y, Soparkar P: Dental caries experience of Kuwaiti schoolchildren. Community Dent Health 2006;23:31-36.

17 Blinkhorn AS, Wainwright-Stringer YM, Holloway PJ: Dental health knowledge and attitudes of regularly attending mothers of high-risk, pre-school children. Int Dent J 2001;51:435-438.
8 Schroth RJ, Brothwell DJ, Moffatt M: Caregiver knowledge and attitudes of preschool oral health and early childhood caries (ECC). Int J Circumpolar Health 2007;66:153-167.

-19 Saied-Moallemi Z, Virtanen JI, Ghofranipour F, Murtomaa H: Influence of mothers' oral health knowledge and attitudes on their children's dental health. Eur Arch Paediatr Dent 2008;9:79-83.

20 Chan SC, Tsai JS, King NM: Feeding and oral hygiene habits of preschool children in Hong Kong and their caregivers' dental knowledge and attitudes. Int J Paediatr Dent 2002;12: 322-331.

21 Kay E, Locker D: A systematic review of the effectiveness of health promotion aimed at improving oral health. Community Dent Health 1998;15:132-144.

22 Kay E, Locker D: Is dental health education effective? A systematic review of current evidence. Community Dent Oral Epidemiol 1996;24:231-235.

23 Ammari JB, Baqain ZH, Ashley PF: Effects of programs for prevention of early childhood caries. A systematic review. Med Princ Pract 2007; 16:437-442. 